\title{
Problems and countermeasures of industrial tourism development in Liaoning Province
}

\author{
Jing $\mathrm{Ha}^{1, *}$, and Cheng Xing ${ }^{2}$ \\ ${ }^{1}$ Master tutor,Ph.D,Shenyang Jianzhu University,China \\ ${ }^{2}$ Master of Shenyang Jianzhu University, China
}

\begin{abstract}
As an old industrial base in the country, Liaoning Province has a solid industrial foundation. The development of industrial tourism in Liaoning Province can not only accelerate the promotion of new industrialization roads, but also contribute to the healthy and sustainable development of the tourism industry in Liaoning Province. This paper analyzes the obstacles and problems in the development of industrial tourism in Liaoning Province at the current stage, and proposes a series of countermeasures to promote the development of industrial tourism in Liaoning Province, which provides ideas for the development and revitalization of industrial tourism.
\end{abstract}

\section{Significance of developing industrial tourism in Liaoning Province}

\subsection{Accelerating the New Industrialization Road in Liaoning Province}

The development of industrial tourism in Liaoning Province can not only promote the optimization and adjustment of the economic and industrial structure and promote the optimization and upgrading of the industry, but also give full play to the pulling effect of tourism on the economy, and have a certain promotion effect on the overall economic development of Liaoning Province.

\subsection{Promote the sustainable development of tourism in Liaoning Province}

Finding out a development model suitable for industrial tourism can not only promote the healthy development of industrial tourism in Liaoning Province, but also further promote the sustainable development of liaoning's tourism.

\subsection{Expanding the Structure and Content of Tourism in Liaoning Province}

Through the deep excavation of industrial tourism resources in Liaoning Province, the typical development structure and content of industrial tourism are summarized and refined, which is conducive to enriching and expanding the overall industrial structure and content of liaoning tourism.

\section{Existing Problems in Liaoning Industrial Tourism}

\subsection{The concept of industrial tourism is outdated}

At present, the enterprises with the potential of developing industrial tourism in Liaoning Province are more conservative, which hinders the development of industrial tourism. The main reasons are as follows: First, Liaoning Province is located in the northeast of the country, and its economic development is slow, which makes people in Liaoning Province have a conservative idea of developing industrial tourism. Many enterprises believe that developing industrial tourism abroad will leak their internal secrets and refuse to develop industrial tourism. Secondly, many enterprises that are still in operation believe that opening their factories to the outside world will affect their normal production. It is this old mindset that limits the development of industrial tourism.

\subsection{Industrial tourism products are monotonous in content and lack of interaction}

The development of industrial tourism products in Liaoning Province is relatively monotonous, which mainly reflects the following aspects: first, industrial tourism is still in the simple stage of sightseeing, lacking tourists' interactive experience in the process of tourism. Second, some industrial enterprises worry about affecting normal production, setting up tourism activities in separate tourism channels or areas, resulting in a boring tourism process. Third, industrial enterprises have not fully developed tourism-related products, lacking 
characteristic and commemorative tourism souvenirs, and tourists have a weak desire to purchase.

\subsection{Lack of integration between industrial and tourism companies}

Industrial tourism in Liaoning Province has just begun, and some industrial enterprises have opened to the outside world spontaneously, attracting tourists to come to visit, in order to achieve the purpose of expanding their popularity. Due to the lack of related knowledge of tourism management and the characteristics of industrial enterprises from an industrial perspective, industrial enterprises cannot fully utilize their unique advantages to carry out tourism activities, which hinders the healthy development of industrial tourism.

\subsection{Incomplete industrial tourism service system}

A high-quality tourism event not only includes various comfortable and tangible reception environments, but also complete intangible services. Some enterprises in Liaoning Province have done a good job in supporting service facilities. However, most industrial enterprises do not consider the safety and comfort of tourists, and the construction of supporting facilities for industrial tourism is relatively backward. Due to the strong leisure and popular science characteristics of industrial tourism, the tourism and industrial knowledge reserve requirements of the reception staff are relatively high. However, most of the tourism reception tasks of liaoning industrial enterprises are performed by redundant employees in the enterprises. They lack professional knowledge in tourism, which leads to poor tourism service quality and difficult to meet the needs of tourists.

\section{Development Countermeasures of Liaoning Industrial Tourism}

\subsection{To create a regional operation mode for industrial tourism}

The so-called industrial tourism regional linkage operation mode mainly includes four levels, which are coordinated with each other. Through the rational development and utilization of liaoning's industrial tourism resources, it can produce agglomeration effect and good driving effect, and promote the healthy and sustainable development of industrial tourism in Liaoning Province.

\subsubsection{Factory area--due to factory conditions and outstanding features}

Industrial enterprise should take advantage of its own advantages, seize the characteristics, and develop selectively to avoid vicious competition of similar industrial enterprises. At the same time, we should also pay attention to the expansion of the industrial chain, strengthen the interaction and participation of tourism, develop unique tourism souvenirs, and constantly improve the attractiveness and competitiveness of industrial tourism.

\subsubsection{Industrial cities--resource integration and joint development}

At this stage Liaoning Province has produced a number of national industrial tourism demonstration sites, distributed in various cities in the province. Liaoning has given full play to the leading role of national industrial tourism demonstration sites and well-known enterprises in the development of industrial tourism, and set up an "industrial enterprise alliance" to improve the overall service level of industrial tourism through industry cooperation and provide boosters for promote the development of tourism industry.

\subsubsection{Industrial city agglomeration -- industrial agglomeration and urban complementarity}

Liaoning Province is rich in industrial tourism resources, but it is scattered in Shenyang, Dalian, Anshan, Fushun, Benxi and other cities. Therefore, the industrial tourism in Liaoning Province should break the regional administrative boundaries, give full play to the resource advantages of each city, fully integrate the industrial tourism resources in Liaoning Province, and form an industrial tourism industry cluster that can drive the economy.

\subsubsection{Inter-provincial industrial city -- breaking down the barriers of inter-provincial administrative division, and cooperating to build a large regional tourism economy}

Integrate the existing industrial tourism resources of Jilin, Inner Mongolia and other surrounding provinces and cities, break the boundaries of administrative divisions, and jointly build a large regional industrial tourism sector. Accelerate the breakthrough of a series of regional, market, and planning obstacles, give play to the combined role of regional alliances, and achieve the integrated and development of the resource market.Liaoning's industrial tourism takes advantage of regional combinations, gradually accelerate the vigorous development of the tourism industry, and form competitiveness in the domestic market, and even enter the ranks of the international tourism market.

\subsection{Develop industrial tourism products with experience to improve the interest}

In the process of industrial tourism development, how to improve the participation and interaction of tourists has become the focus and breakthrough point. Some enterprises that have developed industrial tourism in Liaoning Province have made preliminary attempts, such as Dalian Shengdao glass products factory. But most industrial tourism in Liaoning Province lacks hands-on activities aimed at tourists. For industrial enterprises that 
only focus on visiting and sightseeing, and cannot provide normal production experience for tourists, interactive workshops can be specially set up to allow visitors to act as factory employees, experience the production and life of workers, learn relevant production knowledge, and enhance the interest of industrial tourism.

\subsection{Construct the industrial cultural district and shape the image of urban tourism}

The construction of the image of urban tourism should follow the principle of integrity, pay attention to the preservation of the overall image of industrial culture, and emphasize industrial areas, industrial buildings, facilities and equipment as material carriers. The landscape environment displays the current level of industrial production and production scenes in the form of display boards or walls, perfecting supporting commentary systems, and shaping a complete urban tourism image system.

\subsection{Give play to the characteristics of its resource endowment and innovate the tourism development model}

\subsubsection{Cultural inheritance type development mode}

Cultural heritage type industrial tourism projects are mainly industrial enterprises with certain historical factors and national cultural plots, reflecting the historical development of the industry in miniature. For example,Llaolongkou wine museum and aisin gioro royal wine shop, which are rated as national industrial tourism demonstration sites and 3 a level scenic spots, represent the industrialization level of different development stages of China's industry.

\subsubsection{Modern enterprise visit development mode}

These types of industrial enterprises are the product of China's reform and opening up, and they vividly illustrate the evolution of China's economy. In the process of visiting the enterprise, tourists can understand the culture and advanced management level of the enterprise, and have a sense of trust in the enterprise. For enterprises, this is undoubtedly a very effective way of publicity.Shenyang brilliance BMW, dairy processing, Coca-Cola and snow beer and other enterprises can adopt this mode.

\subsubsection{Art exhibition development mode}

This kind of industrial tourism projects to the manufacturing industry, such as glass, ceramic products porcelain carving and other handicrafts. This type of industrial tourism is characterized by the sale of souvenirs and products as the main content of industrial tourism. The typical representatives of this industrial tourism development mode in Liaoning Province are
Faku ceramic city and Fuxin Fhijiazhi agate city.

\subsubsection{Industrial garden-type development model}

This kind of industrial tourism is in the form of the development of the whole industrial park, which is uniformly managed by the management committee of the industrial park. The industrial tourism projects are also uniformly planned and designed by the management committee of the industrial park.

Such as Tiexi new industrial park, hunnan high-tech industrial park can develop this model.As a dense industrial zone, neat and beautiful factory area and advanced manufacturing technology production line attract more and more tourists to visit.

\subsubsection{Heritage and museum development model}

Due to the adjustment of industrial structure, some kinds of industrial production gradually decline or even close down, leaving a large amount of production space, and these abandoned factories have certain historical and cultural value and memorial significance, these industrial heritage resources can be developed into industrial tourism resources.

Through the transformation of buildings and landscapes, it is the most creative way to transform part of the scattered industrial heritage into a community history gallery and preserve the historical and cultural memory of the city. Combining industrial history with modern development, integrating Shenyang aviation expo park, workers' village life museum, laolongkou wine museum and other exhibition halls with China industrial museum as the core products. According to the time clues, the series of industrial theme museums are drawn up, the industrial theme series museum maps are drawn, the wonderful night theme activities of the industrial museums are organized, the museum discovery journeys of industrial cities are designed, and the profound industrial historical and cultural heritage of Liaoning Province is displayed from all angles.

\subsubsection{Development mode of public recreation space}

In addition, Shenyang workers' village and labor park can develop this mode to reproduce the industrial life and entertainment scenes, provide workers with a rest space, reproduce the scenes of the past, and let workers get back the memories of the past. Through this model, the process of industrial production in Shenyang can be demonstrated, and the characteristics of industrialization in the modern history and development of China can be presented to future generations.

\subsubsection{Commercial comprehensive development and development mode}

Most of these development modes are transformed and reused through industrial sites, and commercial functions are added into urban commercial complexes.Combining industry, parent-child and popular science tourism, it 
provides cultural products with dual functions of entertainment and popular science. The abandoned industrial space will be transformed into an outdoor sports field and a playground will be provided for children to promote parent-child activities and consumption. Creatively designed industrial theme tourism souvenirs have raised the level and level of cultural consumption and expanded the cultural production functions of industrial heritage.

\subsection{Establish a complete system of industrial tourism products with the industrial chain as the link}

With the industrial chain as the main line, diversified industrial tourism theme products and boutique routes are designed to connect the industrial tourism projects of the whole province to form a relatively complete industrial tourism product system, thus driving the economic development of Liaoning Province.

To accelerate the development of Shenyang's tourism equipment manufacturing industry, it is necessary to integrate tourism resources in the equipment manufacturing industry and build a tourism characteristic industrial park integrating design, research and development, production and sales. Only by expanding the brand effect of "Shengjing Haoheer" can we accelerate the application of innovation results.

Industrial tourism focuses on new industrial technology tourism, and promotes the sustainable and healthy development of industrial tourism.

\subsection{Integrated development of industrial tourism and conventional tourism}

The combination of industrial tourism and conventional tourism projects can not only enrich the tourism structure of Liaoning Province, but also highlight the industrial image of Liaoning Province. If the development of industrial tourism alone, it is bound to produce the low survival rate of industrial tourism projects, short life cycle and other development problems. At present, according to the advantages of liaoning's existing industrial tourism resources, it should be integrated with hot spring vacation, natural landscape, cultural landscape, coastal tourism and other projects, so as to make industrial tourism and conventional tourism develop in a coordinated way and form a tourism route with liaoning characteristics.

\section{Summary}

Liaoning province is rich in industrial tourism resources, which lays a good foundation for the development of industrial tourism. In the process of developing industrial tourism, countermeasures should be taken to promote the healthy and sustainable development of industrial tourism in liaoning province.

\section{Project source}

The National Natural Science Foundation of China(51978419); Natural Science Foundation of Liaoning Province(20180551226);

\section{References}

1. Hualin Liu. yuezheng Li. SWOT analysis and development countermeasures of industrial tourism in Liaoning Province $[\mathrm{J}]$. Land and natural resources research,4(2007).

2. Yanzhen Lin. Feasibility analysis and optimization countermeasures of industrial tourism in Liaoning Province [J]. Journal of Dalian university, 8(2008).

3. Tianyuan Li. Introduction to tourism [M]. Tianjin: nankai university press, (2003).

4. Hong Li.Ping Yu. Research on the development potential and development mode of industrial tourism_- Taking liaoning industrial tourism as an example [J]. Journal of Harbin Commercial University (Social Science Edition), (2008).

5. Miaoyan Li.Yingying Wang.Discussion on the Protection of Industrial Heritage and Tourism Development in Liaoning Province [J].Special Zone Economy,(2012). 